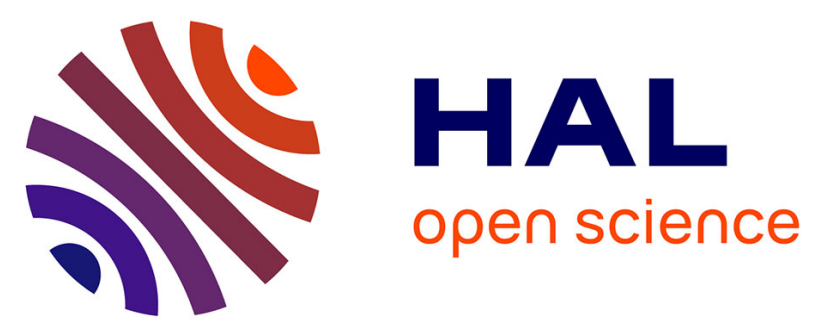

\title{
Effect of vitamin D supplementation on microvascular reactivity in obese adolescents: A Randomized Controlled Trial
}

Agnès Vinet, Christopher Morrissey, Antonia Perez-Martin, Aurélie Goncalves, Cécile Raverdy, Delphine Masson, Sandrine Gayrard, Myriam Carrere, Jean-François Landrier, Marie-Josèphe Amiot

\section{To cite this version:}

Agnès Vinet, Christopher Morrissey, Antonia Perez-Martin, Aurélie Goncalves, Cécile Raverdy, et al.. Effect of vitamin D supplementation on microvascular reactivity in obese adolescents: A Randomized Controlled Trial. Nutrition, Metabolism and Cardiovascular Diseases, 2021, 31 (8), pp.2474-2483. 10.1016/j.numecd.2021.04.025 . hal-03230071

\section{HAL Id: hal-03230071 \\ https://hal.science/hal-03230071}

Submitted on 25 May 2021

HAL is a multi-disciplinary open access archive for the deposit and dissemination of scientific research documents, whether they are published or not. The documents may come from teaching and research institutions in France or abroad, or from public or private research centers.
L'archive ouverte pluridisciplinaire HAL, est destinée au dépôt et à la diffusion de documents scientifiques de niveau recherche, publiés ou non, émanant des établissements d'enseignement et de recherche français ou étrangers, des laboratoires publics ou privés.

\section{(ㅇ)(1) $\$$}

Distributed under a Creative Commons Attribution - NonCommercial - NoDerivatives $\mid 4.0$ 


\section{Journal Pre-proof}

Effect of vitamin D supplementation on microvascular reactivity in obese adolescents: A Randomized Controlled Trial

Agnès Vinet, Christopher Morrissey, Antonia Perez-Martin, Aurélie Goncalves, Cécile Raverdy, Delphine Masson, Sandrine Gayrard, Myriam Carrere, Jean-François Landrier, Marie-Josèphe Amiot

PII: S0939-4753(21)00218-0

DOI: https://doi.org/10.1016/j.numecd.2021.04.025

Reference: NUMECD 2676

To appear in: Nutrition, Metabolism and Cardiovascular Diseases

Received Date: 18 January 2021

Revised Date: 28 April 2021

Accepted Date: 30 April 2021

Please cite this article as: Vinet A, Morrissey C, Perez-Martin A, Goncalves A, Raverdy C, Masson D, Gayrard S, Carrere M, Landrier J-F, Amiot M-J, Effect of vitamin D supplementation on microvascular reactivity in obese adolescents: A Randomized Controlled Trial, Nutrition, Metabolism and Cardiovascular Diseases, https://doi.org/10.1016/j.numecd.2021.04.025.

This is a PDF file of an article that has undergone enhancements after acceptance, such as the addition of a cover page and metadata, and formatting for readability, but it is not yet the definitive version of record. This version will undergo additional copyediting, typesetting and review before it is published in its final form, but we are providing this version to give early visibility of the article. Please note that, during the production process, errors may be discovered which could affect the content, and all legal disclaimers that apply to the journal pertain.

(C) 2021 Published by Elsevier B.V. on behalf of The Italian Diabetes Society, the Italian Society for the Study of Atherosclerosis, the Italian Society of Human Nutrition and the Department of Clinical Medicine and Surgery, Federico II University. 
Effect of vitamin D supplementation on microvascular reactivity in obese adolescents: A Randomized Controlled Trial

Short title: Vitamin D and vascular health in obese adolescents

Key words: Vitamin D / microcirculation / macrocirculation / obese children

Agnès Vinet $^{1 *}$, Christopher Morrissey ${ }^{1 *}$, Antonia Perez-Martin ${ }^{2}$, Aurélie Goncalves $^{3}$, Cécile Raverdy ${ }^{4}$, Delphine Masson ${ }^{4}$, Sandrine Gayrard ${ }^{1}$, Myriam Carrere $^{5}$, Jean-François Landrier ${ }^{6}$, Marie-Josèphe Amiot ${ }^{5}$

* AV and CM contributed equally to this work.

${ }^{1}$ LAPEC EA4278, Université d'Avignon, Avignon, France

${ }^{2}$ Service d'Exploration et Médecine Vasculaire, CHU de Nîmes, Univ Montpellier, France

${ }^{3}$ EA7352 CHROME / APSY-V, Univ. Nîmes, France

${ }^{3}$ Institut Saint Pierre, SSR pédiatrique, Palavas-les-Flots, France

${ }^{5}$ UMR MOISA, Univ Montpellier, CIRAD, CIHEAM-IAM, INRA, Montpellier SupAgro, Montpellier, France

${ }^{6}$ Aix Marseille Université, C2VN, INRAE, INSERM, Marseille, France

Trial registration: NCT02400151 first posted 26/03/2015

Words count: 3580

Keywords: obese adolescents; vitamin D; vascular function

*Corresponding author: 


\section{Agnès VINET}

Avignon University, LAPEC EA4278

74 rue Louis Pasteur

84000 AVIGNON, France

Tel: +33490162930

Fax: + 33490162900

agnes.vinet@univ-avignon.fr 


\section{ABSTRACT}

Background and Aim: Childhood obesity is associated with vitamin D (VD) deficiency and vascular dysfunction. Considering evidence indicates that VD may improve vascular function, this study, for the first time, assessed the effect of VD supplementation on microvascular reactivity in obese adolescents (OA). Methods and Results: This randomized controlled trial included 26 OA, receiving fruit juice with $(n=13)$ or without VD $(4000 \mathrm{IU} / \mathrm{d} ; \mathrm{n}=13)$ over a 3month lifestyle program, as well as 23 normal-weight adolescents (controls). The primary outcome was the pre-to-post-program change in microvascular reactivity determined by laser speckle contrast imaging with acetylcholine and sodium nitroprusside iontophoresis. Changes in 25 hydroxyvitamin $\mathrm{D}(25(\mathrm{OH}) \mathrm{D})$, flow-mediated dilation (FMD), nitrate-mediated dilation (NMD), insulin resistance (HOMA-IR) and inflammatory markers (C-reactive protein [CRP]) were monitored. At inclusion, in comparison to controls, OA exhibited lower total and free 25(OH)D, impaired microvascular responses, and impaired FMD, but similar NMD. After the lifestyle program, total and free $25(\mathrm{OH}) \mathrm{D}$ increased in all $\mathrm{OA}$, with a greater increase in those receiving VD supplements. HOMA-IR and CRP decreased in all OA. Neither FMD nor NMD were altered in either group. Endothelium-dependent microvascular reactivity only increased in the VD-supplemented group, reaching values comparable to that of controls. Similar results were found when analyzing only OA with a VD deficiency at baseline. Conclusion: VD supplementation during a lifestyle program attenuated microvascular dysfunction in $\mathrm{OA}$ without altering macrovascular function. Registration number for clinical trial: NCT02400151. 


\section{INTRODUCTION}

The prevalence in paediatric obesity is a world-wide health issue that, while already burdening public health systems now, has the potential to put an enormous strain on global health resources in the not-so-distant future [1]. Indeed, obesity can have serious health consequences, especially for the vascular system, throughout childhood and adulthood [2]. Previous research has found that childhood obesity is associated with the early signs of endothelium-dependent and -independent vascular dysfunction, not only in the macrocirculation [3-6], but also in the microcirculation [7-9]. Interestingly, the microcirculation is increasingly recognized as an independent site in the development of vascular diseases [10]; collectively highlighting the need to evaluate changes in microvascular health in response to an array of lifestyle and dietary factors across all age groups.

In addition to being linked with vascular dysfunction, obesity in children is also associated with a lower concentration of vitamin D [11-13]. A vitamin D deficiency can be multifactorial, resulting from limited exposure to sunlight, low consumption of vitamin D-rich

food products, larger vitamin D sequestration and/or altered metabolism in adipose tissue [14]. Interestingly, Vitamin D may have a direct role in promoting normal vascular function. Indeed, this vasoprotective property is supported by evidence demonstrating the presence of a vitamin D receptor and 1- $\alpha$ hydroxylase in vascular endothelial cells and vascular smooth muscle cells [15]. Moreover, there is evidence that nitric oxide synthase activity and nitric oxide production is decreased in experimental models where the endothelial vitamin D receptor is lacking [16].

Consistent with this position, vitamin D deficiency in adults has been associated with macrovascular endothelial dysfunction in cross-sectional studies [17,18]; and with microvascular endothelial dysfunction in nephropathy patients, with or without diabetes [19- 
21]. However, observational studies evaluating the association between vitamin D deficiency and vascular dysfunction in obese children were not concordant [22-26]. Additionally, randomized clinical trials examining the macrovascular effect of vitamin D supplementation in adults have been inconclusive so far [27,28]. In obese children, only Javed et al. [25] and Rajakumar et al. [12] have reported that vitamin D supplementation has no impact on macrovascular endothelial function. In a recent meta-analysis in adults [29], based on only 3 trials $[19,30,31]$, there was a small, significant positive-effect of vitamin D supplementation alone on microvascular function (SMD, 0.43; 95\% CI, 0.09-0.76; P=0.01). To date, however, no study has investigated the effect of vitamin D on microvascular function in obese children.

While multidisciplinary weight loss interventions are recommended for paediatric obesity management and for the effective improvement of endothelial function in obese children [32], the potential synergistic effect of vitamin D supplementation combined with a weight-loss program remains unexplored in obese adolescents. Subsequently, the primary aim of this exploratory, double-blind, randomized controlled trial was to investigate the impact of vitamin D supplementation on microvascular reactivity in obese adolescents enrolled in a lifestyle program. Secondarily, this study also aimed to assess if the combined vitamin Dlifestyle intervention mediated any changes in macrovascular reactivity, insulin resistance and inflammatory status.

\section{Materials and Methods}

\section{Study Population}

The VIDADO trial (NCT02400151) is a clinical study designed to examine the effect of a lifestyle program, combined or not combined with vitamin D supplementation, on fat mass 
and cardiovascular-metabolic risk factors in obese adolescents. Twenty-six obese adolescents, 12 to 17 years old, were enrolled in a paediatric weight management clinic in the south of France. Allowing for a case-control study, 23 puberty-matched, normal-weight volunteers were also recruited into the study. To avoid seasonal variations, all adolescents were assessed in either the period April 2015 to July 2015 (1st group) or in the period April 2016 to July 2016 (2nd group). All participants were asked to complete a questionnaire to assess their usual pattern of dietary intake by using a food-frequency questionnaire containing calcium and VD related nutrients. Written, informed consent was obtained from all adolescents and their parents prior to entering the study. The study protocol was conducted in accordance with the declaration of Helsinki.

Body mass index z-scores were calculated. Values greater than 3 defined severe obesity. Exclusion criteria for this study were: history or presence of premature cardiovascular or metabolic disease in a first-degree family member, a current smoking status, regular intake of any medication, pubertal status (less than Tanner stage 2) and current vitamin D supplementation. For obese adolescents, there was specific exclusion criterion, namely weight loss greater than $5 \%$ of total body weight during the previous three months. Normal weight controls were excluded if their body mass index was above the 90th percentile for gender and age. To minimize the potential moderating effects of physical activity, adolescents who participated in extra-school sport activities more than three hours per week were also not included.

Obese adolescents were randomized into two groups, those who received $200 \mathrm{~mL}$ of fruit juice every morning without a vitamin D supplement $(n=13)$ and those who received 200 $m L$ fruit juice every morning with a vitamin $D$ supplement $\left(n=13 ; 4000 \mathrm{IU} / \mathrm{d}\right.$ of Vitamin $\mathrm{D}_{3}$ UVEDOSE 100000 IU/2 mL, Crinex laboratory, France) [33]. The hospitalized adolescents were instructed to drink the fruit juice each morning during breakfast, witnessed by the 
dietician; ensuring $100 \%$ compliance to the study intervention. All obese adolescents entered a three-month lifestyle program. Two of the obese adolescents who were in the group receiving vitamin $\mathrm{D}$ supplements left the clinic before the end of the lifestyle program for personal reasons and were, subsequently, removed from the study (at three months, $\mathrm{n}=11$ ). Throughout the clinic-based lifestyle program, obese adolescents received both standard and personalized meals prescribed by dieticians on a daily basis. The meals were based on a balanced distribution of macronutrients: carbohydrates (55\%), proteins (15\%) and lipids (30\% total, with less than $10 \%$ saturated fat). Their total daily food intake was calculated to enable them to reach a negative energy balance of $500 \mathrm{kcal} / \mathrm{day}$. During the three-month lifestyle program, aerobic training consisted of 180 minutes per week (three sessions of 60 min about $300 \mathrm{kcal}$ per training session) of supervised moderate-to-vigorous intensity exercise as previously described [34].

\section{Demographic, clinical and biological parameters}

Measurement of anthropometrics and biological blood markers were performed at baseline, prior to the beginning of the lifestyle program, in both obese adolescents and normal weight controls, as well as after the three-month program in obese adolescents only. To account for the effect of sun exposure, measurement of 25-hydroxyvitamin D $(25(\mathrm{OH}) \mathrm{D})$ concentrations was also performed after the three-month program in normal-weight controls. Body composition was assessed by dual-energy x-ray absorptiometry. Blood samples were collected to assess the levels of fasting plasma glucose, plasma insulin, high-sensitive C-reactive protein $(\mathrm{CRP})$ and $25(\mathrm{OH}) \mathrm{D}$ concentrations. Serum total $25(\mathrm{OH}) \mathrm{D}$ concentrations were determined by the electrochemiluminescence immunoassay (ECLIA) method, using Roche Diagnostics kits (Roche Elecsys vitamin D total). The lower limit for detection using this method is a concentration of $7.5 \mathrm{nmol} / \mathrm{L}$. The coefficient of variation for each $25(\mathrm{OH}) \mathrm{D}$ 
concentration intra-assay was $<7 \%$. Serum Free $25(\mathrm{OH}) \mathrm{D}$ was quantified by ELISA (DIAsource ImmunoAssays, Louvain-La-Neuve, Belgium). Concentrations of serum CRP were measured according to the manufacturer's specifications using commercially available ELISA kits purchased from R\&D systems (Minneapolis, USA). Insulin resistance was estimated by the calculation of the homeostasis model assessment of insulin resistance (HOMA-IR) index. Blood pressure was measured on the left arm by an automated system (Dinamap, GE Medical Systems, Milwaukee, USA).

\section{Vascular measurements}

Macro- and microvascular assessments were performed at baseline, prior to the beginning of the lifestyle program, in both obese adolescents and normal weight controls; and after the three-month program in obese adolescents only. The adolescents presented to the vascular assessments at least three hours fasted, having abstained from caffeine consumption and strenuous exercise for the 24 hours prior. Vascular assessments were conducted after the adolescents rested in a supine position for 20 minutes, in a room maintained at $22-24^{\circ} \mathrm{C}$. Indeed, the adolescents remained in a supine position throughout the micro- and macrovascular reactivity assessments. All vascular measurements and off-line analyses were performed by two observers (A.V. and C.M.) blinded to group allocation.

Assessments of microvascular reactivity were performed by one investigator (C.M.). Prior to starting the assessments, the arm was immobilized with a vacuum cushion. Changes in cutaneous microvascular blood perfusion were recorded on the ventral face of the forearm skin using a laser speckle contrast imaging system with a laser wavelength of $785 \mathrm{~nm}$ (PeriCam PSI System ${ }^{\circledR}$, Perimed, Järfälla, Sweden). Briefly, laser speckle contrast imaging calculates microvascular blood perfusion by detecting the random speckle pattern generated by the laser light illuminating the moving red blood cells in the skin tissue. The sampling 
frequency was $18 \mathrm{~Hz}$ and the distance between the laser head and skin surface was fixed at $15 \mathrm{~cm}$ (Mahé et al., 2011). The size of the region of interest was approximately $35 \mathrm{~mm}^{2}$ and it was positioned in the middle of the electrode. The perfusion values from the skin were calculated using the manufacturer's software (PimSoft 1.2.2.0®; Perimed, Järfälla, Sweden).

Microvascular reactivity was challenged using transdermal iontophoresis of acetylcholine and sodium nitroprusside, allowing for the assessment of endotheliumdependent and endothelium-independent vasodilation, respectively. Transdermal iontophoresis is a non-invasive method that can move vasoactive drugs, electrically charged molecules, through to the skin blood vessels by use of a device emitting a weak electrical current (PF 751 PeriIont systems, Perimed, Järfälla, Sweden). As recommended by Loader et al. [36], acetylcholine was administered with an anodal current of $0.02 \mathrm{~mA}$ for $200 \mathrm{~s}$ and sodium nitroprusside was administered with a cathodal current of $0.02 \mathrm{~mA}$ for $400 \mathrm{~s}$ concurrently at separate sites. Basal cutaneous blood perfusion was measured by laser speckle contrast imaging for two minutes prior to the beginning of acetylcholine and sodium nitroprusside iontophoresis (200 $\mu \mathrm{l}$ of $1 \%$ solution dissolved in sodium chloride). Indeed, cutaneous blood perfusion was also recorded throughout iontophoresis until there was a plateau in the vascular response to the vasoactive drug being administered. Peak cutaneous blood perfusion values were averaged over a 10 second period at the maximal plateau. The cutaneous blood perfusion responses were expressed in conventional perfusion units (PU) and as the maximum percentage change from baseline.

Macrovascular reactivity was assessed at the brachial artery by the same investigator (A.V.) across all assessments, according to the International Brachial Reactivity Task Force Guidelines and the expert consensus 2019 [37,38]. Brachial artery measurements were captured using high-resolution vascular ultrasonography (MyLab30, Esaote SpA, Firenze, Italy) with a 10-MHz multi-frequency linear probe. B-mode images and Doppler signals were 
continuously and simultaneously recorded for off-line analysis. All results were calculated as the average of five consecutive measurements. To challenge macrovascular endotheliumdependent reactivity, flow mediated dilation (FMD) was performed concurrently to the ultrasonography recordings. Briefly, a pneumatic cuff was put on the right forearm below the elbow. The ultrasound probe was placed approximately midway between the antecubital and axillary regions before the brachial artery diastolic lumen diameter was measured. The cuff was then inflated to $250 \mathrm{~mm} \mathrm{Hg}$ for five minutes before the cuff was rapidly deflated to induce post-ischemic hyperemia, at which point in the assessment the brachial artery diastolic lumen diameter was measured again.

Fifteen minutes after FMD concluded, baseline measurements of the brachial artery diastolic lumen diameter were repeated before $0.4 \mathrm{mg}$ of isosorbide dinitrate (Isocard, Schwarz Pharma, Monheim, Germany) was given sublingually to assess endotheliumindependent vasodilation (i.e. nitrate-mediated dilation, NMD). This procedure has been previously described in detail elsewhere [5,39]. Both FMD and NMD were expressed as the percentage change in peak diastolic brachial artery lumen diameter after reactive hyperemia and exogenous organic nitrate administration, respectively, relative to the baseline diastolic diameter. Time-averaged mean blood flow velocity and blood flow were determined. Shear rate $\left(\mathrm{s}^{-1}\right)$ was calculated as $4 \times$ time-averaged mean blood flow velocity/mean brachial diameter, to estimate peak shear stress [40]. Within-subject coefficient of variations in our laboratory at rest were $1.8 \%$ for arterial diameters and 12.7\% for FMD [41].

\section{Statistical analyses}

Statistical analyses were performed with SPSS ${ }^{\circledR}$ software (IBM Corp, Armonk, NY). The primary outcome variable was the percentage change in microvascular blood perfusion in response to acetylcholine iontophoresis. The sample size was calculated by considering a type 
I error rate of 5\% (2-tailed) and a power of 90\% based on the results from Dreyer et al. [19]. Calculations indicated that a sample size of eight participants was required in each group to achieve statistical power. Due to the small sample size $(<30)$, non-parametric statistical tests involving median comparisons were performed. Firstly, Mann-Whitney Tests were performed to check for differences between obese adolescents and normal weight controls at baseline. Additionally, Mann-Whitney tests were performed to check for baseline differences between the group of obese adolescents receiving vitamin D supplements and those who were not. Wilcoxon Signed-Rank tests were used to compare the effect of the lifestyle program combined with vitamin D supplementation to the effects of the lifestyle program alone. Spearman correlations were used to identify associations between baseline values and any change in vascular variables and $25(\mathrm{OH}) \mathrm{D}$. Accordingly, the change in outcomes between groups was compared using an alternative non-parametric ANCOVA [42] using ranked change from baseline variability and ranked the baseline HOMA-IR values. For follow-up analysis, a subgroup analysis with only the 18 obese adolescents deficient in vitamin D at baseline was also performed.

\section{RESULTS}

The main clinical characteristics of the adolescents are presented in Table 1. At baseline, as expected, obese adolescents had a significantly higher body mass index, body mass index-Z score and fat mass than normal weight controls. Obese adolescents also had significantly lower total and free $25(\mathrm{OH}) \mathrm{D}$ concentrations, higher systolic and lower diastolic blood pressures, a greater HOMA-IR index and higher CRP levels than normal weight controls. Vitamin D deficiency (defined by $25(\mathrm{OH}) \mathrm{D}$ concentration $\left.<50 \mathrm{nmol} . \mathrm{L}^{-1}\right)$ [43] was detected in 
$73 \%(18 / 26)$ of the obese adolescents and in only $22 \%(5 / 23)$ of the normal weight controls. A 3-day dietary recall and food frequency questionnaire was administered to quantify the adolescent's vitamin D food sources (e.g. egg yolk, fatty fishes, fortified dairy products and mushrooms). The median intake was 1.6 microg (min: 0.82 max: 7.41). Only, three obese adolescents had an intake up to 5 microg, equivalent to $200 \mathrm{UI}$, which is three times less than the recommendation from the Institute of Medicine (600 UI); confirming inadequate dietary intake of VD in obese adolescents. Between the two subgroups of obese adolescents, those who were not receiving vitamin D supplements and those who were, there were no differences in age or in any of the clinical or biological parameters, except for HOMA-IR and diastolic blood pressure, which was higher and lower, respectively, in those consuming vitamin D supplements.

While peak shear rate and NMD did not differ between groups, obese adolescents had a lower FMD than normal weight controls (Table 2). Noting that baseline cutaneous blood perfusion values did not differ between obese adolescents and normal weight controls, the microvascular dilatory response to acetylcholine and sodium nitroprusside iontophoresis, expressed as a percentage increase from baseline, was also lower in obese adolescents. Prior to entering the lifestyle program, there was no difference in any of the parameters of macroand microvascular reactivity between those randomized to receive vitamin D supplements and those who were not. Concentrations of total $25(\mathrm{OH}) \mathrm{D}$ were correlated with acetylcholinemediated increases in cutaneous blood perfusion in the obese adolescents with a vitamin D deficiency at baseline $(\mathrm{n}=18, \mathrm{r}=0.582, \mathrm{p}=0.002)$.

After the three-month lifestyle program, total and free $25(\mathrm{OH}) \mathrm{D}$ increased while body mass index, HOMA-IR and CRP decreased in those who were receiving vitamin D supplements, as well as in those who were not (Table 3). In normal-weight adolescents, after three months, an increase in $25(\mathrm{OH}) \mathrm{D}$ was also observed $(+20 \%$, data not shown). Vitamin D 
deficiency was attenuated (i.e. Vitamin D concentrations raised above $50 \mathrm{nmol} / \mathrm{L}$ ) in all obese adolescents receiving vitamin D supplements and in $70 \%(9 / 13)$ of those who were not. Moreover, the increase in total $25(\mathrm{OH}) \mathrm{D}$ after adjustment for ranked baseline HOMA-IR index, was significantly greater in obese adolescents receiving vitamin D supplements (Table 4).

The vasodilatory response to acetylcholine iontophoresis increased in those receiving vitamin D supplements to a point where there was no longer a difference in microvascular reactivity between those obese adolescents and the normal weight controls. Interestingly, the same improvement in vascular reactivity, was not observed in the obese adolescents who completed the lifestyle program but did not receive vitamin D supplements (Figure 1). Indeed, the increase in endothelium-dependent and endothelium-independent microvascular reactivity after adjustment for ranked baseline HOMA-IR index, was significantly greater in obese adolescents receiving vitamin $\mathrm{D}$ supplements. The post-lifestyle program increases in the microvascular responses to acetylcholine tended to be correlated with the increase in 25(OH)D ( $\mathrm{r}=0.38, \mathrm{p}=0.09)$. Neither FMD nor NMD changed in either of the subgroups of obese adolescents (Figure 2). The results remained the same even when performing a subgroup analysis that included only the 16 obese adolescents with a vitamin D deficiency at baseline.

\section{DISCUSSION}

The main finding of this exploratory, double-blind, randomized controlled trial is that vitamin

D supplementation during a lifestyle program in obese adolescents improved endotheliumdependent microvascular reactivity without any effect on macrovascular function. This result 
suggests that vitamin D is beneficial to microvascular health, furthering its importance from a paediatric health standpoint.

In accordance with previous research, this study confirmed that vitamin D deficiency and obesity are interrelated. Indeed, similarly to Ganji et al. [44], more than $70 \%$ of the obese adolescents included in this study had a vitamin D deficiency prior to entering the lifestyle program. The findings from the assessments of macrovascular reactivity in this study also supported those of previous research $[4,45]$, even when discrepancies were reported $[5,46]$. In addition to confirming an impairment in endothelium-dependent macrovascular reactivity in obese adolescents, this study also demonstrated an impairment in both endothelium-dependent and endothelium-independent microvascular reactivity; supporting data from previous studies in obese children [9].

Whether vitamin D deficiency and vascular dysfunction are associated in obese children has remained hitherto inconclusive. In this present study, there was no relationship between total or free 25(OH)D and FMD in all obese adolescents, supporting findings of previous studies $[22,25,26]$. In contrast, the significant correlation between total $25(\mathrm{OH}) \mathrm{D}$ and acetylcholine-mediated vasodilation in vitamin D-deficient obese adolescents at baseline was a major and novel finding. Vitamin D may have a specific mechanism of action on microcirculation [19], altering the structure and arrangement of the microvasculature by binding to the endothelium's vitamin D receptor and stimulating the synthesis of nitric oxide, a powerful vasodilator; and by reducing the production of reactive oxygen species that decrease nitric oxide bioavailability [47].

The effects of vitamin D supplementation in obese children are still poorly understood [48], especially when considering its impact on vascular function. The lifestyle program in this study, consisting of diet control, exercise and vitamin D supplementation, coincided with an improvement in total and free $25(\mathrm{OH}) \mathrm{D}$ concentrations in all obese adolescents, 
presumably due to both a possible release of VD during weight loss and to sun exposure. Interestingly, the sole weight-loss program improved the VD status in obese adolescents not receiving VD supplements, as previously reported [49,50]; noting that this study was carried in the south of France during the spring and that the increased sun exposure would also have contributed to endogenous VD biosynthesis in the obese adolescents (i.e $+20 \%$ in normalweight). The weight-loss program also improved HOMA-IR with the greatest enhancement obtained in the obese adolescent receiving VD supplements. The role of vitamin D in the regulation of insulin sensitivity has been highlighted [51]. However, Nader et al. [52] found that vitamin D supplementation has no effect on HOMA-IR in obese adolescents. There were also distinctive changes in vascular reactivity, dependent on the artery type. Indeed, there was no change in macrovascular reactivity. A recent meta-analysis in adults reported that vitamin D supplementation alone had no effect on endothelial function [28,29]. The only two studies in obese children that have investigated the effect of vitamin D supplementation on macrovascular function confirmed this lack of effect $[12,25]$. The null effect of the combined lifestyle program (diet and exercise with vitamin D supplementation) on macrovascular function was a novel finding in this present study.

In contrast, this clinical trial demonstrated an improvement in endothelium-dependent microvascular reactivity after the three-month lifestyle program in obese adolescents receiving vitamin D supplements. These vascular data suggest that physiological differences in the control of vasomotion between small and large blood vessels may underpin the difference in the response to vitamin D supplementation [29]. The lifestyle program combined with vitamin D supplementation resulted in a significant increase in endothelium-dependent microvascular reactivity. In a recent meta-analysis in adults that included three studies that assessed the microcirculation [29], it was reported that vitamin D supplementation alone had a small, but significant benefit, for microvascular reactivity (SMD, 0.43; 95\% CI, 0.09-0.76; 
$\mathrm{P}=0.01)[19,30,31]$. The clinical significance of this result is not clear. The increase in microvascular function was not associated with decreased inflammation state, body mass index nor HOMA-IR after the weight-loss program. Nevertheless, even if there were no associations between those parameters, it cannot be excluded that the lifestyle intervention could have a mediating role in the effect of VD on microvascular reactivity. Indeed, it is not well understood how increases in the concentration of $25(\mathrm{OH}) \mathrm{D}$ could improve vascular function and it is beyond the scope of this study's data to expand on the current body of mechanistic knowledge.

This study is strengthened by its double blind, randomized controlled design, by administering vitamin D supplements in accordance with the international guidelines reported in Saggese et al. [53], by the $100 \%$ compliance rate in obese adolescents and by the assessment of both microvascular and macrovascular reactivity. However, the present study has several limitations. The relatively small sample size included in this study limits extrapolation of any findings to a wider population. Unfortunately, $1,25(\mathrm{OH}) 2 \mathrm{D}$, and the synthesis of vitamin D-binding proteins were not monitored in this study. Furthermore, no parathyroid hormone concentrations were available. Additionally, vascular comparisons with normal weight adolescents were only completed at baseline and not after the three-month lifestyle program. Finally, it remains unclear what proportion of influence each interventional factor, diet, exercise or vitamin D supplementation, had on the positive outcomes in $25(\mathrm{OH}) \mathrm{D}$ concentration and vascular profiles reported in this study.

In conclusion, our data indicate for the first time that daily vitamin D supplementation in conjunction with a lifestyle program, which controls calory intake and exercise habits, can significantly improve microvascular function in obese adolescents. Considering the small sample of obese adolescents enrolled in this trial, future research needs to confirm the findings of this study in a larger population before vitamin D supplementation can be 
recommended in a lifestyle program to counteract microvascular impairment in childhood obesity.

Conflict of interest: Authors have no conflicts of interest to disclose.

Acknowledgements: The study was supported in part by the University Hospital of Nimes, France (grant LOCAL/2015). English language editing was provided by Dr. Jordan Loader of Uppsala University, Sweden, and proofyourscience.com. 


\section{FIGURE LEGENDS}

Figure 1: The percentage increase in cutaneous blood perfusion from baseline measurements following iontophoresis with $\mathrm{A}$ ) acetylcholine (ACh) and B) sodium nitroprusside (SNP), before and after the intervention in both subgroups of obese adolescents, those who were receiving vitamin D supplements (OS) and those who were not (ONS).

Figure 2: A) flow-mediated dilation (FMD) and B) nitrate-mediated dilation (NMD) before and after the intervention in both subgroups of obese adolescents, those who were receiving vitamin D supplements (OS) and those who were not (ONS). 


\section{References}

1. Tirosh A, Shai I, Afek A, et al. Adolescent BMI trajectory and risk of diabetes versus coronary disease. N Engl J Med. 2011;364(14):1315-1325. doi:10.1056/NEJMoa1006992

2. Must A, Jacques PF, Dallal GE, Bajema CJ, Dietz WH. Long-term morbidity and mortality of overweight adolescents. A follow-up of the Harvard Growth Study of 1922 to 1935. N Engl J Med. 1992;327(19):1350-1355. doi:10.1056/NEJM199211053271904

3. Aggoun Y, Farpour-Lambert NJ, Marchand LM, Golay E, Maggio ABR, Beghetti M. Impaired endothelial and smooth muscle functions and arterial stiffness appear before puberty in obese children and are associated with elevated ambulatory blood pressure. Eur Heart J. 2008;29:792-799. doi:10.1093/eurheartj/ehm633

4. Karpoff L, Vinet A, Schuster I, et al. Abnormal vascular reactivity at rest and exercise in obese boys. Eur J Clin Invest. 2009;39:94-102. doi:10.1111/j.1365-2362.2008.02068.x

5. Montero D, Walther G, Perez-Martin A, et al. Effects of a lifestyle program on vascular reactivity in macro- and microcirculation in severely obese adolescents. J Clin Endocrinol Metab. 2014;99:1019-1026. doi:10.1210/jc.2013-3394

6. Zócalo Y, Marotta M, García-Espinosa V, et al. Children and Adolescents Macrovascular Reactivity Level and Dynamics, But Not the Microvascular Response, is Associated with Body Mass Index and Arterial Stiffness Levels. High Blood Press. Cardiovasc Prev J Ital Soc Hypertens. 2017;24:371-386. doi:10.1007/s40292-017-02072

7. Bhattacharjee R, Alotaibi WH, Kheirandish-Gozal L, Capdevila OS, Gozal D. Endothelial dysfunction in obese non-hypertensive children without evidence of sleep disordered breathing. BMC Pediatr. 2010;10:8. doi:10.1186/1471-2431-10-8

8. Hedvall Kallerman P, Hagman E, Edstedt Bonamy A-K, et al. Obese children without comorbidities have impaired microvascular endothelial function. Acta Paediatr Oslo Nor. 2014;103:411-417. doi:10.1111/apa.12549

9. Schlager O, Willfort-Ehringer A, Hammer A, et al. Microvascular function is impaired in children with morbid obesity. Vasc Med Lond Engl. 2011;16:97-102. doi:10.1177/1358863X11400780

10. Wiernsperger N, Rapin JR. Microvascular diseases: is a new era coming? Cardiovasc Hematol Agents Med Chem. 2012;10(2):167-83.

11. Alemzadeh R, Kichler J, Babar G, Calhoun M. Hypovitaminosis D in obese children and adolescents: relationship with adiposity, insulin sensitivity, ethnicity, and season. Metabolism. 2008;57:183-191. doi:10.1016/j.metabol.2007.08.023

12. Rajakumar K, C M, A K, et al. Effect of vitamin D3 supplementation on vascular and metabolic health of vitamin D-deficient overweight and obese children: a randomized clinical trial. Am J Clin Nutr. 2020;00:1-12. 
13. Turer CB, Lin H, Flores G. Prevalence of vitamin D deficiency among overweight and obese US children. Pediatrics. 2013;131:152-161. doi:10.1542/peds.2012-1711

14. Pourshahidi L. Vitamin D and obesity: current perspectives and future directions. Proc Nutr Soc. 2015;74(2):115-24.

15. Molinari C, Uberti F, Grossini E, et al. 1 $\alpha, 25$-dihydroxycholecalciferol induces nitric oxide production in cultured endothelial cells. Cell Physiol Biochem Int J Exp Cell Physiol Biochem Pharmacol. 2011;27(6):661-668. doi:10.1159/000330075

16. Ni W, Watts SW, Ng M, Chen S, Glenn DJ, Gardner DG. Elimination of vitamin D receptor in vascular endothelial cells alters vascular function. Hypertens Dallas Tex. 2014;64:1290-1298. doi:10.1161/HYPERTENSIONAHA.114.03971

17. Al Mheid I, Patel R, Murrow J, et al. Vitamin D status is associated with arterial stiffness and vascular dysfunction in healthy humans. J Am Coll Cardiol. 2011;58(2):186-192. doi:10.1016/j.jacc.2011.02.051

18. Yiu Yf, Chan Yh, Yiu Kh, et al. Vitamin D deficiency is associated with depletion of circulating endothelial progenitor cells and endothelial dysfunction in patients with type 2 diabetes. J Clin Endocrinol Metab. 2011;96(5):E830-5. doi:10.1210/jc.2010-2212

19. Dreyer G, Tucker AT, Harwood SM, Pearse RM, Raftery MJ, Yaqoob MM. Ergocalciferol and microcirculatory function in chronic kidney disease and concomitant vitamin d deficiency: an exploratory, double blind, randomised controlled trial. PloS One. 2014;9:99461. doi:10.1371/journal.pone.0099461

20. Karonova T, Stepanova A, Bystrova A, Jude EB. High-Dose Vitamin D

Supplementation Improves Microcirculation and Reduces Inflammation in Diabetic Neuropathy Patients. Nutrients. 2020;12(9):2518. doi:10.3390/nu12092518

21. Munisamy S, Kamaliah Md, Suhaidarwani Ah, Zahiruddin Wm, Rasool Ah. Impaired microvascular endothelial function in vitamin D-deficient diabetic nephropathy patients. J Cardiovasc Med Hagerstown Md. 2013;14(6):466-471. doi:10.2459/JCM.0b013e3283590d3d

22. Ashraf A, Alvarez J, Dudenbostel T, et al. Associations between vascular health indices and serum total, free and bioavailable 25-hydroxyvitamin D in adolescents. PloS One. Published online 2014. doi:10.1371/journal.pone.0114689

23. Bacha F, Klinepeter Bartz S, Tomsa A, Sharma S. Free Vitamin D: Relationship to Insulin Sensitivity and Vascular Health in Youth. J Pediatr. 2019;212:28-34.

24. Codoñer-Franch P, Tavárez-Alonso S, Murria-Estal R, Megías-Vericat J, TortajadaGirbés M, Alonso-Iglesias E. Nitric oxide production is increased in severely obese children and related to markers of oxidative stress and inflammation. Atherosclerosis. 2011;215:475-480. doi:10.1016/j.atherosclerosis.2010.12.035

25. Javed A, Kullo IJ, Balagopal PB, Kumar S. Effect of vitamin D3 treatment on endothelial function in obese adolescents. Pediatr Obes. 2016;11:279-284. doi:10.1111/ijpo.12059 
26. Pacifico L, Anania C, Osborn JF, et al. Low 25(OH)D3 levels are associated with total adiposity, metabolic syndrome, and hypertension in Caucasian children and adolescents. Eur J Endocrinol. 2011;165:603-611. doi:10.1530/EJE-11-0545

27. Hussin A, Ashor A, Schoenmakers I, Hill T, Mathers Jc, Siervo M. Effects of vitamin D supplementation on endothelial function: a systematic review and meta-analysis of randomised clinical trials. Eur J Nutr. 2017;56(3):1095-1104. doi:10.1007/s00394-0161159-3

28. Mazidi M, Karimi E, Rezaie P, Vatanparast H. The impact of vitamin D supplement intake on vascular endothelial function; a systematic review and meta-analysis of randomized controlled trials. Food Nutr Res. 2017;61:1273574.

doi:10.1080/16546628.2016.1273574

29. Beveridge LA, Khan F, Struthers AD, et al. Effect of Vitamin D Supplementation Markers Vasc Funct Syst Rev Individ Particip Meta-Anal. J Am Heart Assoc. 2018;7. doi:10.1161/JAHA.117.008273

30. Stricker H, Tosi Bianda F, Guidicelli-Nicolosi S, Limoni C, Colucci G. Effect of a single, oral, high-dose vitamin D supplementation on endothelial function in patients with peripheral arterial disease: a randomised controlled pilot study. Eur J Vasc Endovasc Surg J Eur Soc Vasc Surg. 2012;44:307-312. doi:10.1016/j.ejvs.2012.06.023

31. Witham MD, Adams F, Kabir G, Kennedy G, Belch JJF, Khan F. Effect of short-term vitamin D supplementation on markers of vascular health in South Asian women living in the UK-a randomised controlled trial. Atherosclerosis. 2013;230:293-299. doi:10.1016/j.atherosclerosis.2013.08.005

32. Montero D, Walther G, Perez-Martin A, Roche E, Vinet A. Endothelial dysfunction, inflammation, and oxidative stress in obese children and adolescents: markers and effect of lifestyle intervention. Obes Rev Off J Int Assoc Study Obes. 2012;13(5):441-455. doi:10.1111/j.1467-789X.2011.00956.x

33. Biancuzzo RM, Young A, Bibuld D, et al. Fortification of orange juice with vitamin $\mathrm{D}(2)$ or vitamin $\mathrm{D}(3)$ is as effective as an oral supplement in maintaining vitamin $\mathrm{D}$ status in adults. Am J Clin Nutr. 2010;91(6):1621-1626. doi:10.3945/ajcn.2009.27972

34. Morrissey C, Montero D, Raverdy C, Masson D, Amiot M-J, Vinet A. Effects of Exercise Intensity on Microvascular Function in Obese Adolescents. Int J Sports Med. 2018;39(6):450-455. doi:10.1055/a-0577-4280

35. Mahé G, Haj-Yassin F, Rousseau P, et al. Distance between laser head and skin does not influence skin blood flow values recorded by laser speckle imaging. Microvasc Res. 2011;82(3):439-442. doi:10.1016/j.mvr.2011.06.014

36. Loader J, Roustit M, Taylor F, et al. Assessing cutaneous microvascular function with iontophoresis: Avoiding non-specific vasodilation. Microvasc Res. 2017;113:29-39. doi:10.1016/j.mvr.2017.04.006

37. Corretti MC, Anderson TJ, Benjamin EJ, et al. International Brachial Artery Reactivity Task Force, 2002. Guidelines for the ultrasound assessment of endothelial-dependent 
flow-mediated vasodilation of the brachial artery: a report of the International Brachial Artery Reactivity Task Force. J Am Coll Cardiol. 39:257-265.

38. Thijssen D, Bruno R, van Mil A, et al. Expert consensus and evidence-based recommendations for the assessment of flow-mediated dilation in humans. Eur Heart $J$. 2019;40(30):2534-2547. doi:10.1093/eurheartj/ehz350

39. Vinet A, Obert P, Courteix D, et al. Different modalities of exercise improve macrovascular function but not microvascular function in metabolic syndrome: The RESOLVE randomized trial. Int J Cardiol. 2018;267:165-170. doi:10.1016/j.ijcard.2018.05.073

40. Wray DW, Uberoi A, Lawrenson L, Richardson RS. Heterogeneous limb vascular responsiveness to shear stimuli during dynamic exercise in humans. J Appl Physiol Bethesda Md 1985. 2005;99(1):81-86. doi:10.1152/japplphysiol.01285.2004

41. Walther G, Nottin S, Karpoff L, Pérez-Martin A, Dauzat M, Obert P. Flow-mediated dilation and exercise-induced hyperaemia in highly trained athletes: comparison of the upper and lower limb vasculature. Acta Physiol Oxf Engl. 2008;193(2):139-150. doi:10.1111/j.1748-1716.2008.01834.x

42. Conover $\mathrm{W}$ and Iman R. Analysis of covariance using the rank transformation. Biometrics 1982; 38:715-724.

43. Giovannucci E. Vitamin D, how much is enough and how much is too much? Public Health Nutr. 2011;14(4):740-1. doi:10.1017/S1368980011000243

44. Ganji V, Zhang X, Shaikh N, Tangpricha V. Serum 25-hydroxyvitamin D concentrations are associated with prevalence of metabolic syndrome and various cardiometabolic risk factors in US children and adolescents based on assay-adjusted serum 25hydroxyvitamin D data from NHANES 2001-2006. Am J Clin Nutr. 2011;94:225-233. doi:10.3945/ajen.111.013516

45. Cote A, Harris Kc, Panagiotopoulos C, Sandor Gg, Devlin Am. Childhood obesity and cardiovascular dysfunction. J Am Coll Cardiol. 2013;62(5):1309-1319.

doi:10.1016/j.jacc.2013.07.042

46. Charakida M, Jones A, Falaschetti E, et al. Childhood obesity and vascular phenotypes: a population study. J Am Coll Cardiol. 2012;60:2643-2650. doi:10.1016/j.jacc.2012.08.1017

47. Mutlu U, Ikram Ma, Hofman A, et al. Vitamin D and retinal microvascular damage: The Rotterdam Study. Medicine (Baltimore). 2016;95(49):e5477. doi:10.1097/MD.0000000000005477

48. Szlagatys-Sidorkiewicz A, Brzeziński M, Jankowska A, Metelska P, Słomińska-Frączek $M$, Socha P. Long-term effects of vitamin D supplementation in vitamin D deficient obese children participating in an integrated weight-loss programme (a double-blind placebo-controlled study) - rationale for the study design. BMC Pediatr. 2017;17(1):97. doi:10.1186/s12887-017-0851-7 
49. Hossain MJ, Levinson A, George D et al. Vitamin D status and cardiovascular risk in obesity: effect of physical activity in nonvitamin D supplemented adolescents. Metab Syndr Relat Disord. 2018; 16: 197-203.

50. Reinehr T, de Sousa G, Alexy U et al. Vitamin D status and parathyroid hormone in obese children before and after weight loss. Eur. J. Endocrinol. 2007; 157: 225-232.

51. Teegarden D, Donkin SS. Vitamin D: emerging new roles in insulin sensitivity. Nutr Res Rev. 2009;22(1):82-92. doi:10.1017/S0954422409389301

52. Nader NS, Aguirre Castaneda R, Wallace J, Singh R, Weaver A, Kumar S. Effect of vitamin D3 supplementation on serum $25(\mathrm{OH}) \mathrm{D}$, lipids and markers of insulin resistance in obese adolescents: a prospective, randomized, placebo-controlled pilot trial. Horm Res Paediatr.

53. Saggese G, Vierucci F, Prodam F, et al. Vitamin D in pediatric age: consensus of the Italian Pediatric Society and the Italian Society of Preventive and Social Pediatrics, jointly with the Italian Federation of Pediatricians. Ital J Pediatr. 2018;44(1). doi:10.1186/s13052-018-0488-7 
Table 1: Baseline characteristics of the participants

\begin{tabular}{|c|c|c|c|c|c|c|}
\hline \multirow{2}{*}{ Characteristics } & \multirow{2}{*}{$\begin{array}{c}\text { All obese } \\
\text { adolesents } \\
(n=26)\end{array}$} & \multicolumn{2}{|c|}{ Obese adolescent subgroups } & \multirow{2}{*}{$\begin{array}{c}\text { P value } \\
\text { OS vs } \\
\text { ONS }\end{array}$} & \multirow{2}{*}{$\begin{array}{l}\text { Normal-weight } \\
\qquad(\mathrm{n}=23)\end{array}$} & \multirow{2}{*}{$\begin{array}{c}\text { P value } \\
\text { All obese vs } \\
\text { NW } \\
\end{array}$} \\
\hline & & OS $(n=13)$ & ONS $(n=13)$ & & & \\
\hline \multicolumn{7}{|l|}{ Demographics } \\
\hline Age-yr & $14.2(13.6-14.8)$ & $14.6(13.6-14.8)$ & $14(13.1-16.7)$ & .959 & $14.9(14.2-15.3)$ & 0.193 \\
\hline Sex $(M-F)$ & $10-16$ & $5-8$ & $5-8$ & 1.0 & $10-13$ & .728 \\
\hline \multicolumn{7}{|l|}{ Clinical parameters } \\
\hline BMI $\left(\mathrm{kg} / \mathrm{m}^{2}\right)$ & $33.5(31.2-36.2)$ & $33.8(31.3-36.5)$ & $32.7(31.1-36.3)$ & 0.614 & $19.2(18.5-20.2)$ & $<.0001$ \\
\hline BMI Z-score & $4.0(3.5-4.5)$ & $3.9(3.4-4.7)$ & $4.0(3.4-4.6)$ & 0.959 & $0.1(-0.3-0.7)$ & $<.0001$ \\
\hline Fat mass $(\%)$ & $41.4(39.8-43.2)$ & $41.9(39.8-43.6)$ & $41.1(36.5-44.3)$ & 0.555 & $23.2(18.4-27.7)$ & $<.0001$ \\
\hline SBP (mmHg) & $112(106-120)$ & $112(106-123)$ & $113(106-120.5)$ & 0.797 & $105(102-109)$ & $<.001$ \\
\hline $\mathrm{DBP}(\mathrm{mmHg})$ & $66(62-68)$ & $59(57-60)$ & $61(59-68)$ & 0.039 & $67(63-69)$ & .006 \\
\hline \multicolumn{7}{|l|}{ Biological parameters } \\
\hline Total 25(OH)D (nmol/L) & $38(35.4-47.8)$ & $39(38-55.8)$ & $34.5(32-58.6)$ & 0.191 & $62(55-68.3)$ & $<.0001$ \\
\hline $\mathrm{n}$ deficiency in $25(\mathrm{OH}) \mathrm{D}<37.5 \mathrm{nmol} / \mathrm{L}$ & 8 & 1 & 7 & - & 0 & - \\
\hline$n$ insuficiency in $25(\mathrm{OH}) \mathrm{D}<50 \mathrm{nmol} / \mathrm{L}$ & 18 & 9 & 9 & - & 5 & - \\
\hline Free $25(\mathrm{OH}) \mathrm{D}(\mathrm{pg} / \mathrm{mL})$ & $4.1(1.9-5.3)$ & $4.1(1.9-5.3)$ & $4.1(2.4-4.8)$ & 0.918 & $4.8(2.6-6.2)$ & .006 \\
\hline HOMA-IR & $4.0(3.3-5.6)$ & $5.6(3.5-6.7)$ & $3.4(2.3-4.0)$ & 0.01 & $2.23(1.4-2.8)$ & $<.0001$ \\
\hline $\mathrm{CRP}(\mathrm{mg} / \mathrm{mL})$ & $6.1(3.3-10.1)$ & $7.9(3.6-13.7)$ & $4.4(2.3-10.1)$ & 0.331 & $0.3(0.2-0.9)$ & $<.0001$ \\
\hline
\end{tabular}

BMI, body mass index; CRP, C-reactive protein; DBP, diastolic blood pressure; HOMA-IR, homeostasis model assessment-insulin resistance; OS, obese participants receiving vitamin D supplements; ONS, obese participants not receiving vitamin D supplements; SBP, systolic blood pressure; $25(\mathrm{OH}) \mathrm{D}$, 25 hydroxyvitamin D.

Data are expressed as median and 95\%CI for the median. 
Table 2: Baseline vascular characteristics of the participants

\begin{tabular}{|c|c|c|c|c|c|c|}
\hline \multirow[b]{2}{*}{ Vascular Parameters } & \multirow{2}{*}{$\begin{array}{l}\text { Normal-weight } \\
\quad(n=23)\end{array}$} & \multirow{2}{*}{$\begin{array}{l}\text { All obese } \\
(n=26)\end{array}$} & \multirow{2}{*}{$\begin{array}{c}\text { P value } \\
\text { All obese vs } \\
\text { NW } \\
\end{array}$} & \multicolumn{2}{|c|}{ Obese adolescents subgroups } & \multirow{2}{*}{$\begin{array}{c}\mathrm{P} \text { value } \\
\text { OS vs ONS }\end{array}$} \\
\hline & & & & OS $(n=13)$ & ONS $(n=13)$ & \\
\hline \multicolumn{7}{|c|}{ Macrocirculation } \\
\hline FMD $(\%)$ & $9.60(7.69-12.93)$ & $6.66(5.13-8.09)$ & 0.015 & $6.06(3.22-10.52)$ & $6.89(5.19-8.77)$ & 0.442 \\
\hline Peak shear rate $\left(\mathrm{s}^{-1}\right)$ & $637.8(569.0-753.5)$ & $587.1(507.6-660.2)$ & 0.206 & $598.7(490.7-737.8)$ & $578.2(406.7-763.1)$ & 0.699 \\
\hline FMD/deltaSR $\left(\% . \mathrm{s}^{-1}\right)$ & $0.019(0.015-0.036)$ & $0.014(0.011-0.023)$ & 0.141 & $0.012(0.007-0.024)$ & $0.019(0.009-0.039)$ & 0.349 \\
\hline $\operatorname{NMD}(\%)$ & $22.25(18.18-29.21)$ & $19.35(15.41-22.38)$ & 0.107 & $16.61(12.24-20.90)$ & $20.34(15.80-26.24)$ & 0.061 \\
\hline \multicolumn{7}{|c|}{ Microcirculation } \\
\hline Resting CBF (PU) & $34.0(28.0-38.0)$ & $36.2(34.2-41.7)$ & 0.119 & $36.2(32.9-41.4)$ & $38.1(31.2-45.5)$ & 0.852 \\
\hline Peak ACh CBF (PU) & $95.8(69.7-100.2)$ & $69.3(64.7-81.5)$ & 0.075 & $68.7(55.8-76.0)$ & $74.2(62.4-106.0)$ & 0.198 \\
\hline ACh CBF increase (\%) & $150.0(121.3-187.2)$ & $113.3(69.6-136.5)$ & 0.008 & $80.7(40.5-134.3)$ & $124.8(77.6-148.7)$ & 0.198 \\
\hline Peak SNP CBF (PU) & $78.4(69.7-106-4)$ & $71.7(60.4-76.1)$ & 0.064 & $62.4(45.8-73.8)$ & $75.5(59.7-87.2)$ & 0.119 \\
\hline SNP CBF increase $(\%)$ & $136.0(86.7-170.9)$ & $94.6(42.5-123.8)$ & $\mathbf{0 . 0 3 3}$ & $53.3(36.2-117.9)$ & $120.4(72.5-153.1)$ & 0.080 \\
\hline
\end{tabular}

Ach, acetylcholine; CBF, cutaneous blood flow; FMD, flow-mediated dilation; NMD, nitrate-mediated dilation; OS, obese participants receiving vitamin D supplements; ONS, obese participants not receiving vitamin D supplements; SNP CVC, sodium nitroprusside cutaneous vascular conductance; SR, shear rate.

Data are expressed as median and $95 \% \mathrm{CI}$ for the median. 
Table 3: Changes in characteristics in the obese adolescents after completing the 3-month lifestyle intervention

\begin{tabular}{lcccc}
\hline & \multicolumn{2}{c}{ OS $(\mathrm{n}=11)$} & \multicolumn{2}{c}{ ONS $(\mathrm{n}=13)$} \\
\cline { 2 - 5 } \multicolumn{1}{c}{ Outcome variables } & Baseline & 3 -months & Baseline & $3-$ months \\
\hline Total 25(OH)D $(\mathrm{nmol} / \mathrm{L})$ & $39(38-55.8)$ & $70(59.8-91.7)^{* * *}$ & $34.5(32-58.6)$ & $60(40.2-70.5)^{* * *}$ \\
Free $25(\mathrm{OH}) \mathrm{D}(\mathrm{pg} / \mathrm{mL})$ & $4.1(1.9-5.3)$ & $6.6(4.4-8.3)^{* *}$ & $4.1(2.4-4.8)$ & $5.5(4.1-8.1)^{* *}$ \\
BMI $\left(\mathrm{kg} / \mathrm{m}^{2}\right)$ & $33.8(31.3-36.5)$ & $31.6(28.7-33.1)^{* * *}$ & $32.7(31.1-36.3)$ & $30.1(29.2-32.7)^{* * *}$ \\
HOMA-IR & $5.6(3.5-6.7)$ & $3.3(2.9-4.2)^{* *}$ & $3.4(2.3-4.0)$ & $2.3(1.4-3.1)^{*}$ \\
CRP $(\mathrm{mg} / \mathrm{mL})$ & $7.9(3.6-13.7)$ & $6.5(1-7.9)^{*}$ & $4.4(2.3-10.1)$ & $1.8(0.7-2.5)^{* *}$ \\
\hline
\end{tabular}

BMI, body mass index; CRP, C-reactive protein; HOMA-IR, homeostasis model assessment-insulin resistance; OS, obese participants receiving vitamin D supplements; ONS, obese participants not receiving vitamin D supplements; $25(\mathrm{OH}) \mathrm{D}, 25$ hydroxyvitamin $\mathrm{D}$. * $\mathrm{p}<0.05, * * \mathrm{p}<0.01$, $* * * \mathrm{p}<0.001$ between baseline and 3-months.

Data are expressed as median and 95\%CI for the median. 
Table 4 : Changes in biological characteristics within and between the two subgroups of obese adolescents, those who were receiving vitamin D supplements and those who were not

\begin{tabular}{|c|c|c|c|c|c|}
\hline \multirow[t]{2}{*}{ Parameters } & \multicolumn{2}{|c|}{ OS } & \multicolumn{2}{|c|}{ ONS } & \multirow[b]{2}{*}{$\begin{array}{l}\mathrm{p} \text { value for the } \\
\text { difference between } \\
\text { groups\# }\end{array}$} \\
\hline & median (IQ)* & $\begin{array}{l}\mathrm{p} \text { value for the } \\
\text { difference within } \\
\text { group }{ }^{\dagger}\end{array}$ & median (IQ)* & $\begin{array}{l}\mathrm{p} \text { value for the } \\
\text { difference within } \\
\text { group } \dagger\end{array}$ & \\
\hline HOMA-IR & $-2.7(-4.5,-0.5)$ & $p=0.008$ & $-0.8(-1.3,0.07)$ & $p=0.019$ & $p=0.005$ \\
\hline CRP (mg/mL) & $-3.5(-6.8,-0.5)$ & $p=0.038$ & $-2.5(-7.5,0.9)$ & $p=0.004$ & $\mathrm{p}=0.884$ \\
\hline ACh CBF increase $(\%)$ & $49.3(34.7-133.2)$ & $p=0.039$ & $7.9(-13.9-70.2)$ & $\mathrm{p}=0.469$ & $p=0.002$ \\
\hline SNP CBF increase $(\%)$ & $49.9(-24.2-141.9)$ & $\mathrm{p}=0.105$ & $-10.6(-37.0-49.3)$ & $\mathrm{p}=0.831$ & $p=0.035$ \\
\hline
\end{tabular}

CRP, C-reactive protein; FMD, flow-mediated dilation; HOMA-IR, homeostasis model assessment-insulin resistance; IQ, interquartile range; OS, obese participants receiving vitamin D supplements; ONS, obese participants not receiving vitamin D supplements; 25(OH)D, 25 hydroxyvitamin D. * Difference, 3 month follow-up minus baseline; $\dagger p$ values are based on the Wilcoxon signed-rank test to compare the baseline and 3 months values within each group; \# p values are based on fitting an analysis of non-parametric ANCOVA using ranked change from baseline variability and ranked baseline HOMA-IR values to compare the changes between the two groups. 
A

$-\bullet \cdot$ ONS $\rightarrow$ OS

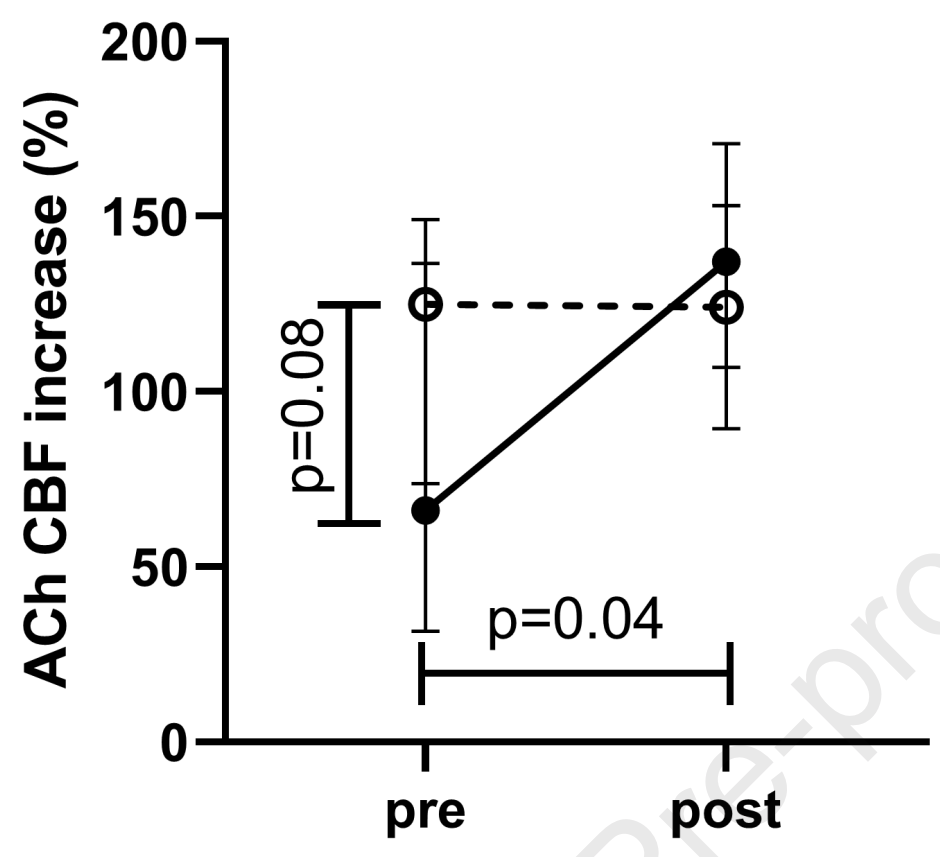

B

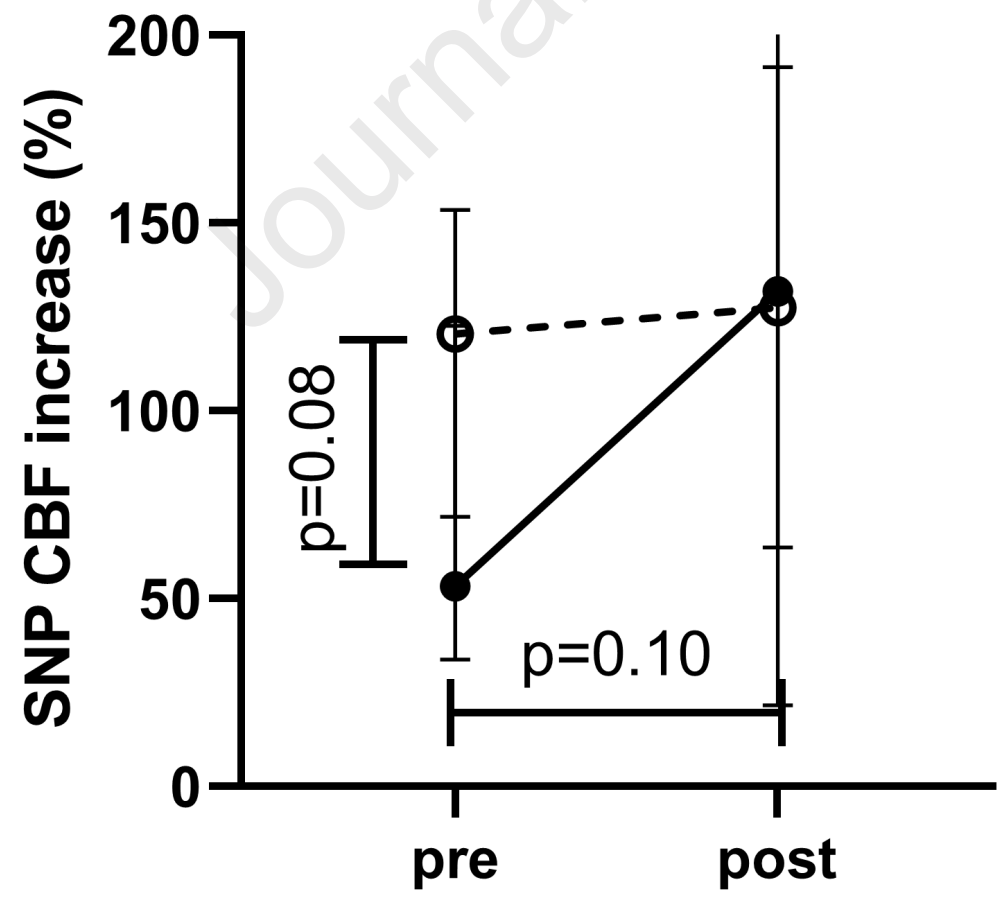


$-\circ \cdot$ ONS $\rightarrow$ OS

A
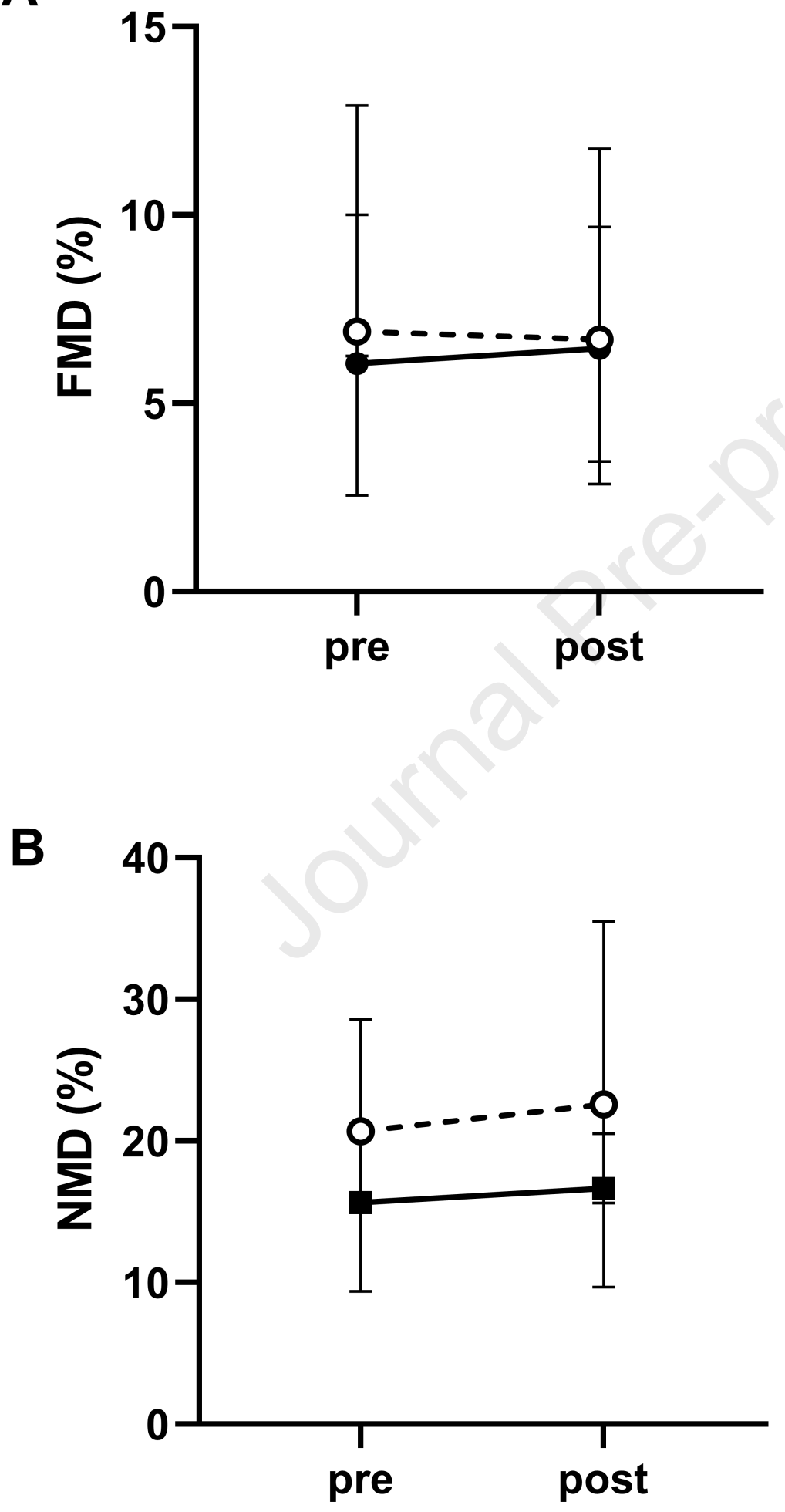


\section{Highlights}

- VD deficiency is associated with endothelial dysfunction in obese adolescents.

- VD supplementation improved microvascular function in obese adolescents.

- VD supplementation had no effect on macrovascular function in obese adolescents. 